\title{
Correction to: Selected future tasks in electrochemical research related to advanced power sources
}

\author{
David Malka $^{1} \cdot$ Netanel Shpigel ${ }^{1} \cdot$ Ran Attias $^{1} \cdot$ Doron Aurbach $^{1}$
}

Published online: 9 July 2020

(C) Springer-Verlag GmbH Germany, part of Springer Nature 2020

\section{Correction to: Journal of Solid State Electrochemistry} https://doi.org/10.1007/s10008-020-04694-z

This original article contained a mistake.

Author name "Nethanel Shpigel" should be presented as "Netanel Shpigel" as correctly shown above.

The original article has been corrected.

Publisher's note Springer Nature remains neutral with regard to jurisdictional claims in published maps and institutional affiliations.

The online version of the original article can be found at https://doi.org/ $10.1007 / \mathrm{s} 10008-020-04694-\mathrm{Z}$

Doron Aurbach

Doron.Aurbach@biu.ac.il

1 Department of Chemistry and BINA-BIU Center for Nanotechnology and Advanced Materials, Bar-Ilan University, 5290002 Ramat-Gan, Israel 